\title{
O USO DA TELEVISÃO DIGITAL NO CONTEXTO EDUCATIVO
}

\author{
Marcelo Sacrini
}

\section{RESUMO}

O artigo apresenta uma reflexão sobre a utilização cultural e educativa de um sistema digital de televisão como forma de promover o acesso à informação para a construção e transformação do conhecimento. Aborda as potenciais formas de uso dos recursos da televisão digital no contexto educativo, num momento que antecede à escolha do modelo tecnológico de referência para o país. Apresenta os padrões existentes e o movimento governamental na escolha do sistema brasileiro. A partir da pesquisa documental, o artigo reúne informações sobre as aplicações da televisão digital nesse contexto: a migração das emissoras para o novo sistema; o uso como repositório de programas culturais e educativos; a implementação de uma rede de intercâmbio baseada no suporte digital; além do protótipo de uso da TV Escola Digital Interativa, a proposta do SAPSA - Serviço de Apoio ao Professor em Sala de Aula e a possibilidade do documentário digital interativo enquanto exemplo de conteúdo educativo, pela apropriação dos recursos.

\section{PALAVRAS-CHAVE}

Televisão digital; Educação e tecnologia; TV digital interativa

\section{THE USE OF THE DIGITAL TELEVISION IN THE EDUCATIVE CONTEXT}

\begin{abstract}
The article present a reflection about the cultural and educational use of a television digital system as a form to increase the information access to build and transform the knowledge. It approaches the potential forms of use of the resources of the digital television in the educative context, at a moment that it precedes to the choice of the technological model of reference for the country. It presents the existing standards and the governmental movement in the choice of the Brazilian system. From the documentary research, the article congregates information about the applications of the digital television in this context: the migration of the senders for the new system; the use as repository of cultural and educative programs; the implementation of a net of interchange based on the digital support; beyond the archetype of use of the TV Interactive Digital School, the proposal of the SSPC Service of Support to the Professor in Classroom and the possibility of the interactive digital set of documents while example of educative content, for the appropriation of the resources.
\end{abstract}

\section{KEYWORDS}

Digital television; Education and technology; Interactive digital TV 


\section{INTRODUÇÃO}

A televisão é o principal meio de comunicação de massa e fonte de informação, entretenimento e consumo da maior parte das populações de países em todo o mundo. A supremacia do aparato se consolidou aos poucos desde o seu surgimento, em meados do século XX, mas principalmente após o rápido desenvolvimento tecnológico que possibilitou a portabilidade dos equipamentos, a produção de programas longe da frieza dos estúdios e próxima à verdade explícita das ruas, ou ainda a invenção do vídeo-tape e a disseminação das locadoras de filmes nos anos 1980, a explosão do uso dos videocassetes que rapidamente se configurariam no aparelho que sinalizou para uma futura segmentação dos conteúdos, possibilitada em seguida pelas novas tecnologias.

Um pouco depois do surgimento da televisão, e com grande vigor a partir dos anos 1990 até a atualidade, os computadores foram inventados e vêm se sofisticando cada vez mais, consolidando-se, pela sua natureza, enquanto ferramenta de interação entre os indivíduos pela possibilidade da conexão em rede, e ainda como aparato-chave de uma nova sociedade informacionalista, apoiada nas tecnologias da inteligência e viabilizada numa configuração social que é estruturada pela integração das redes, assuntos amplamente discutidos por Castells (2005) e Lévy (2000) em seus estudos.

A principal característica da televisão convencional analógica diz respeito ao tipo de difusão do conteúdo. Normalmente, um conteúdo televisivo é criado para atender a um público-alvo bastante diverso e abrangente. Embora a segmentação já seja possível em sistemas mais avançados de transmissão, em sua história essa possibilidade foi sempre muito restrita.

O computador em rede, por sua vez, permite uma personalização cada vez mais eficiente do conteúdo acessado pelo usuário por meio da recuperação de informações específicas conforme o seu interesse. Os sistemas computacionais e a comunicação pela Internet podem organizar para o usuário dados absolutamente individualizados, conforme hábitos de navegação registrados pelos marcadores de acesso ${ }^{1}$ ou outros dispositivos técnicos, por meio do protocolo $\mathrm{IP}^{2}$.

\footnotetext{
${ }^{1}$ Os cookies, arquivos gravados no sistema do usuário quando ele visita algum conteúdo da rede mundial de computadores, são um exemplo dessa forma registro por marcadores de acesso.

${ }^{2}$ Internet Protocol
} 
Já implementada e em uso em alguns países desenvolvidos, se vislumbra uma possibilidade bastante próxima de convergência tecnológica desses dois recursos também no Brasil, configurando um novo equipamento que integra sistemas digitalizados de produção e envio de conteúdos audiovisuais interativos, numa interface já consagrada, a algumas possibilidades da sua conexão em rede e uso de canal de retorno, o que virá a ser a Televisão Digital Interativa.

Trata-se da televisão como a conhecemos com os processos de produção, encapsulamento, envio e recepção de sinais totalmente digitalizados. Dependendo do sistema adotado, poderão ser incorporadas algumas possibilidades de interação do usuário com o sistema, com o conteúdo, entre conteúdos, ou com seus provedores. Assim, a apropriação de uma televisão que é digital, e que poderá ser interativa, deve transformar o meio que lhe deu origem, se configurando num novo ambiente de comunicação e interação que soma características e possibilidades de diversos suportes pré-existentes.

Uma discussão que acompanha a existência dos dois equipamentos, televisão e computador, está relacionada com a utilização desses aparatos tecnológicos no contexto educativo pelas sociedades que incorporam seus recursos. O presente trabalho pretende acoplar à discussão já em andamento sobre o uso dos computadores nos procedimentos pedagógicos uma possibilidade de apropriação e uso efetivo e crítico da televisão digital nos processos de aquisição e construção do conhecimento.

\section{METODOLOGIA}

A partir da pesquisa documental (LAKATOS ; MARCONI, 2001), o artigo vai recuperar e agrupar algumas informações sobre as aplicações plausíveis ao uso da televisão digital nos processos educativos: seu aproveitamento enquanto espaço para veiculação de programas culturais interativos e de entretenimento educativo pela migração das emissoras para o novo sistema; sua utilidade enquanto repositório de programas para acesso ondemand $^{3}$, que poderão ser produzidos e distribuídos por provedores de conteúdos; sua utilização por uma rede de intercâmbio das televisões universitárias; a apresentação da experiência da TV Escola Digital Interativa; a proposta do SAPSA - Serviço de Apoio ao Professor em Sala de Aula, além do exemplo de uma aplicação específica, pela apresentação do documentário digital interativo. Antes, irá mostrar alguns modelos tecnológicos 
existentes e elaborar um breve histórico das ações oficiais do Governo no caminho da decisão que ainda não aconteceu, em maio de 2005, sobre o padrão tecnológico a ser adotado no Brasil.

Não serão escopo deste estudo as aplicações relacionadas ao ensino a distância, exatamente por compreender que a importância da utilização da televisão digital nesse contexto de ensino requer uma pesquisa específica quanto às possibilidades de uso. Servirá, porém, para subsidiar os trabalhos futuros ao identificar algumas potencialidades para a utilização do aparato com esse objetivo.

\section{TELEVISÃO DIGITAL: ALGUNS MODELOS TECNOLÓGICOS}

A grande discussão antecedente à definição de um padrão tecnológico para a televisão digital brasileira traz consigo aspectos que extrapolam a simples escolha de um modelo, mas que têm relação com o deslocamento de volumes consideráveis de investimentos na direção do padrão eleito. Sendo assim, é natural que indústria, empresas de comunicação e de tecnologia, assim como grupos econômicos de diversos segmentos participem e interfiram na decisão do Governo, como também é natural que esta será resultado de pareceres técnicos somados a essas interferências. Salienta-se, aqui, que o aspecto político da decisão não é objetivo deste estudo.

Independente da definição do modelo tecnológico a ser escolhido, ou do desenvolvimento de um padrão próprio para o país, a abordagem necessária para o presente trabalho é voltada mais às possibilidades de utilização do aparato depois de desenvolvido que para os pontos inerentes ao processo político-decisório, principalmente pelo foco nas aplicações no contexto educativo, pretendido aqui.

Ainda assim, considera-se importante um conhecimento, mesmo que preliminar, sobre os modelos existentes, já que trazem características que podem modificar o olhar sobre as possibilidades de sua utilização e sobre a elaboração dos conteúdos.

Três sistemas disputam o aval oficial para serem implementados como padrão nacional: o primeiro, baseado no padrão norte-americano; um segundo, baseado no padrão europeu; e o terceiro, que tem base no padrão japonês. Há também uma possibilidade de

\footnotetext{
${ }^{3}$ Sob demanda.
} 
desenvolvimento de um sistema brasileiro, que pretende incorporar características e qualidades dos 3 padrões apresentados anteriormente.

Becker e Montez (2004, p.127-136) apresentam os principais modelos de televisão digital disponíveis, com destaque aos padrões já consolidados, conforme descritos brevemente a seguir.

O modelo ATSC - Advanced Television Systems Committee funciona nos Estados Unidos desde 1998, e é também adotado pelo Canadá, Coréia do Sul e Taiwan. O sistema privilegia a alta qualidade de imagem (HDTV) e som (Dolby AC-3), características buscadas pelo mercado consumidor norte-americano. O meio de transmissão predominante é o sistema a cabo (pago), cuja infra-estrutura cobre cerca de 95\% dos domicílios daquele país (CPQD, 2002b, p.32).

O padrão europeu é conhecido como DVB - Digital Video Broadcasting e é adotado nos paises da Europa, além da Austrália, Malásia, Hong Kong, Índia, África do Sul entre outros. A Inglaterra tem o sistema digital mais consolidado, funcionando desde 1993, com difusão tanto a cabo, como via satélite e terrestre. O foco de utilização desse padrão está voltado para a prestação de serviço com grande interatividade: serviços de Internet, portais, provimento de conteúdos e serviços de telefonia. Apesar de o sistema ser pago, muitas vezes os equipamentos são subsidiados pelas operadoras de TV.

O Japão desenvolve isoladamente o sistema ISDB - Integrated Services Digital Broadcasting desde 1999, para privilegiar uma maior flexibilidade de operações e a utilização em suportes portáteis e móveis. A plataforma revela o intuito do modelo japonês em somar alta definição de imagem com serviços interativos, características dos dois sistemas apresentados antes.

O governo brasileiro delegou ao CPqD - Fundação Centro de Pesquisa e Desenvolvimento em Telecomunicações a tarefa de elaborar alguns estudos necessários para subsidiar a decisão sobre o modelo a ser adotado no país, o que pode envolver a escolha de um dos modelos já existentes ou o desenvolvimento de um padrão nacional próprio de televisão digital.

É importante acrescentar à lista dos modelos apresentados aqui a pesquisa em andamento desenvolvida pela China, que tem a capacidade de fabricar mais de 40 milhões de 
aparelhos de televisão anualmente (FNDC, 2005b) e pode rapidamente desenvolver os equipamentos para a disseminação da tecnologia. Houve, em abril de 2005, uma aproximação por interesses comuns entre Ministério das Comunicações do Brasil e o governo daquele país, em relação ao desenvolvimento de um modelo tecnológico para a televisão digital que agregue as características esperadas por ambos para o sistema. A China entra, com grande destaque, na disputa para a adoção de seu futuro padrão também no Brasil.

\section{DIRETRIZES DO GOVERNO BRASILEIRO PARA A ESCOLHA DO MODELO}

Segundo o Ministério das Comunicações, o Brasil possui cerca de 54 milhões de televisores em 87\% dos lares brasileiros (1,4 tv/lar). Desses, 79\% recebem a transmissão via radiodifusão terrestre, em sinal aberto, motivo pelo qual o Governo se empenha na definição de um padrão também aberto para a televisão digital no país. ${ }^{4}$

Baseado nesses números, o Ministro de Estado das Comunicações publicou em 2002 o documento Exposição de Motivos (Brasil, 2002), no qual ratifica a importância da televisão digital aberta gratuita para a educação e cultura no país e aponta, no anexo sobre Política para Adoção de Tecnologia Digital no Serviço de Radiodifusão de Sons e Imagens, o empenho em promover a inclusão digital como finalidade expressiva da implementação do modelo terrestre no Brasil.

Em 2003, o presidente da república baixou o decreto que instituiu o SBTVD Sistema Brasileiro de Televisão Digital (BRASIL, 2003). A instituição tem, entre seus fins, o objetivo de planejar e viabilizar o processo de transição da televisão analógica para o sistema digital. Além disso, ficou mais uma vez definida no decreto a intenção de "promover a inclusão digital” e "propiciar a criação de rede universal de educação a distância”. 5

Com o desdobramento dessas diretrizes em pesquisas encomendadas pelo Governo, o $\mathrm{CPqD}$ trabalha na elaboração dos documentos que subsidiarão a decisão sobre o padrão técnico para o Sistema Brasileiro de Televisão Digital. As pesquisas da Fundação fazem parte do Projeto TV Digital Interativa, financiado com recursos do Funttel - Fundo para Desenvolvimento Tecnológico das Telecomunicações. O Governo destinará cerca de R\$ 65 milhões em recursos para o projeto, a ser conduzido por consórcios entre Universidades, instituições e centros nacionais de pesquisa (CPQD, 2005a).

\footnotetext{
${ }^{4}$ Dados obtidos no sítio do Ministério das Comunicações na Internet. Disponível em http://www..mc.gov.br/

${ }^{5}$ Termos destacados do Artigo $1^{\circ}$, Inciso $n^{\circ}$ II.
} 
Vários documentos já foram divulgados pelo Ministério das Comunicações para o desenvolvimento do debate nacional, com destaque aos que compuseram o Projeto - Modelo de Implantação da TV Digital no Brasil, Relatórios Produto I, II e III, elaborados pelo CPqD (CPQD, 2002a, 2002b e 2002c). Os documentos traçam um panorama mundial da implantação da tecnologia digital na transmissão terrestre de televisão à época da definição dos modelos em diversos países do mundo, e apontam as similaridades com a realidade brasileira.

A grande penetração da televisão no território nacional é a principal justificativa do Governo em querer consolidar o modelo terrestre aberto, e gratuito, para a televisão digital do país, com foco voltado à educação e à difusão da cultura, conforme os documentos já referidos. As diretrizes mostram uma necessidade de incorporar características bastante específicas ao modelo escolhido para o Brasil, que estejam mais adequadas às realidades sócio-cultural e econômica de um país continente onde as discrepâncias sociais predominam que àquelas dos países onde os padrões já estão consolidados.

Em janeiro de 2005, o CPqD divulgou o documento Cadeia de Valor (CPQD, 2005b), com cerca de 100 páginas sobre como poderá ser constituída a relação econômica e social entre os segmentos da sociedade e do Estado envolvidos com a televisão e as telecomunicações na transição da tecnologia analógica para o modelo digital. O Ministério das Comunicações apontou o documento como o primeiro de uma série de oito outros que serão ainda produzidos, até dezembro de 2005, para subsidiar o debate que resultará na escolha do modelo de referência do SBTVD (FNDC, 2005b). O mesmo prazo foi apontado pelo Secretário Executivo do Ministério das Comunicações, Paulo Lustosa, para a entrega de um relatório do comitê gestor responsável pela avaliação e análise das questões referentes (FNDC, 2005a). Segundo o Ministério, a decisão sobre qual padrão vai adotar para a televisão digital no Brasil deve acontecer em fevereiro de 2006.

\section{O USO DA TELEVISÃO DIGITAL NO CONTEXTO EDUCATIVO}

Toda experiência de uso de novos aparatos tecnológicos nos processos educativos de ensino e aprendizagem gera sempre grandes expectativas quanto aos resultados prometidos, sem às vezes levar em conta as implicações que envolvem a utilização desses recursos, não raramente sub-utilizados ou explorados de forma inadequada e pouco produtiva. Ainda assim, 
sabe-se que o uso das tecnologias digitais em rede, por exemplo, possibilita novas formas de produção e acesso a informações antes restritas, permitindo a construção do conhecimento num grau jamais visto.

Parte-se sempre do pressuposto de que a utilização de aparatos tecnológicos em sala de aula ou em momentos informais de aprendizagem pode promover uma melhoria nos processos cognitivos do indivíduo, ou serve de elemento diferencial que o motiva a se envolver com os conteúdos para a construção de algum conhecimento.

O mesmo fenômeno será novamente experimentado com o uso da televisão digital nesse contexto e, embora haja muitas expectativas, sabe-se que o uso efetivo depende das possibilidades adensadas pela tecnologia somadas a uma adequada qualificação daquele que a utiliza, problema recorrente nessas questões.

O modelo de televisão digital escolhido pelo Governo deverá integrar transmissão terrestre de sinais, satélite, telefonia fixa e Internet em banda larga para tornar disponível aos usuários textos, imagens e som. Diferentemente do sistema original analógico, a televisão digital possibilitará a transmissão de conteúdos complementares, guias didáticos e de orientação, tabelas, artigos, além de conteúdos que poderão ser enviados de volta ao provedor do serviço ou da programação ${ }^{6}$. A recepção via satélite e o retorno possibilitado pelas redes de telefonia fixa têm alcance em praticamente todo o território brasileiro.

Dentre as principais inovações com o uso da televisão digital no contexto educativo, podemos esperar aquelas relacionadas com as aplicações multimídias e a conexão do aparato em rede, por meio de protocolos específicos ou já utilizados na rede mundial de computadores. Essa possibilidade permitirá ao usuário interagir e intervir na produção dos conteúdos. Para os processos de ensino e aprendizagem, pode significar um avanço sem precedentes no meio televisivo, pois irá compor, num mesmo aparato, recursos e sistemas de informação que exploram determinados assuntos com uma possibilidade de interação entre as partes desse sistema, essencial para alguma avaliação daquilo que foi apreendido.

Nesse sentido, a ferramenta possibilitará o exercício completo das atividades educativas por meio de recursos audiovisuais com o apelo das já consagradas transmissões

\footnotetext{
${ }^{6}$ Depende da existência de um canal de retorno, que envia sinais e dados para a solicitação e/ou agendamento de conteúdos extras e serviços. A opção mais adequada e de maior capilaridade é a utilização da rede de telefonia fixa instalada no país.
} 
televisivas, permitindo uma reconfiguração das formas de contato com o conhecimento a partir do oferecimento de "serviços para a teleducação que têm como eixo uma pedagogia comunicacional de apoio ao professor em sala de aula, apoio ao estudante em casa e interação pais-escola” (AMARAL ; PACATA, 2003).

Essa utilidade, já experimentada na rede mundial de computadores, promoverá mais uma vez a possibilidade de favorecer de várias maneiras o domínio do conhecimento de forma mais rápida e eficiente do que aquela possível com o audiovisual convencional ou de suporte apenas impresso.

É bem conhecido o papel fundamental do envolvimento pessoal do aluno no processo de aprendizagem. Quanto mais ativamente uma pessoa participar da aquisição de um conhecimento, mais ele irá integrar e reter aquilo que aprender. Ora, a multimídia interativa, graças à sua dimensão reticular e não linear, favorece uma atitude exploratória, ou mesmo lúdica, face ao material a ser assimilado. É, portanto, um instrumento bem adaptado a uma pedagogia ativa. (LÉVY, 2000, p.40)

O presente trabalho traz um breve compêndio das potenciais formas de utilização e aproveitamento da televisão digital em contextos de aprendizagem e ensino, como proposta de acoplar ao âmbito do debate técnico, já há algum tempo em desenvolvimento, uma discussão de caráter social quanto ao enfoque educativo do modelo, empenho expresso nos documentos oficiais do Governo.

A grande discussão no lançamento de um novo sistema de televisão aportado numa tecnologia inovadora e bastante recente traz consigo o debate sobre a disputa em torno da ocupação do espectro de banda existente para o oferecimento dos programas, entendidos daqui por diante como uma convergência cada vez mais intensa de produtos e serviços e a decorrente potencialidade para o desenvolvimento de negócios inerentes.

Fica evidente que, pela grandeza dos investimentos despendidos tanto por parte das iniciativas privadas como aqueles fomentados pelo Governo, a nova televisão será predominantemente comercial e deverá atender às lógicas de mercado do sistema capitalista prevalecente. Isso significa que, sem o investimento dos grupos econômicos potentes, e aí podemos entendê-los tanto como a indústria de eletrônica quanto as empresas de telecomunicações com respaldo financeiro, não teremos uma televisão digital abrangente, principalmente se dependermos apenas das iniciativas estatais para o seu desenvolvimento.

Ainda assim, há uma possibilidade de ampliação das vozes nesse contexto específico, caso o Governo aponte para um regimento que permita a inserção de grupos 
economicamente menos privilegiados na exploração desse meio. Sabe-se, por exemplo, que o novo sistema ampliará em cerca de dez vezes a oferta de canais. Basta, portanto, e isso é considerável se comparado à situação da ocupação dos espaços televisivos observada no presente, permitir que comunidades e grupos sociais não voltados aos interesses mercantilistas realmente ocupem seus nichos, pressupondo que eles existirão no novo sistema. Num modelo ideal, permitir, inclusive, que o indivíduo produza e divulgue seus próprios conteúdos televisivos, uma possibilidade propícia ao sistema de conexão em rede, como já experimentado pela Internet.

A tv digital abre as portas, de uma maneira muito especial, para a alfabetização audiovisual permanente, possibilitando e fomentando nos espectadores a capacidade de produzir e analisar suas próprias mensagens (...) propiciando uma educação que promova uma intervenção social e coletiva crítica imprescindível para uma formação de cidadania (AMARAL ; PACATA, 2003).

A primeira possibilidade de utilização cultural e educativa de um sistema digital de televisão é a natural migração das emissoras pré-existentes ao novo modelo, com a incorporação dos recursos que estarão disponíveis e todas as inovações decorrentes. Essa migração é ensaiada já há algum tempo pelas grandes emissoras, desde quando iniciaram a substituição dos seus equipamentos analógicos por aparatos digitais de captura, tratamento e distribuição dos conteúdos.

Poderemos ter uma revolução na forma de assistir a televisão quando, por exemplo, o modelo de canais for substituído pela composição de uma grade própria de programação montada pelo usuário, uma evolução dos Eletronic Programme Guides (GAWLINSKI, 2003, p.7), que apresentam a programação organizada numa linha de tempo, já comuns em sistemas de tv a cabo e via satélite (por assinatura). A possibilidade de manipulação dessa grade de programação será viabilizada pela forma como os programas poderão ser buscados e recuperados pelo aparelho conectado ao sistema, e acessados no horário definido pelo usuário.

Além desse recurso, Gawlinski (2003, p.6-26) ainda apresenta outras possibilidades típicas do sistema digital de televisão que, já experimentadas em emissoras pelo mundo, certamente poderão ser consideradas como serviços inovadores se adotados no modelo brasileiro. São eles: Teletext-style Services, pelo qual o usuário tem acesso a uma gama de informações e serviços de um dado canal (emissora), que deixaria de apenas transmitir programas para se transformar numa central informativa de serviços e entretenimento. 
Os Walled Gardens são composições de serviços interativos especialmente preparados para a televisão digital tendo em vista a utilização comercial do sistema. Será a utilização mais promissora, pois permitirá o acesso a produtos e serviços para a aquisição instantânea por meio da interação do usuário com a televisão. A qualquer momento, ao passar pelos programas, o telespectador deverá encontrar formas de acesso a menus com alusão a termos como “interatividade” ou "serviços”, a partir dos quais poderá acessar shoppings virtuais ou serviços que são pagos imediatamente.

A Internet on Television poderá fazer a ponte de acesso da televisão digital com a rede mundial de computadores, a partir de conteúdos específicos que terão de estar adequados para a navegação no ambiente televisivo. O recurso poderá trazer o acesso a serviços já consagrados na rede, como a visualização de e-mails ou dispositivos de comunicação instantânea. Sabe-se, porém, que a postura do usuário frente à televisão em nada se assemelha ao seu comportamento diante de um microcomputador. A migração da Internet para a televisão é, portanto, muito discutida e esbarra nos aspectos da adequação dessas interfaces e nas características específicas de uso de cada um dos aparatos que acessam os sistemas.

Enhanced Television é o nome dado por Gawlinski (2003, p.17) às possibilidades de intervenção imediata do telespectador diante do conteúdo de um programa. Servirá para a manifestação de sinais de aceitação ou de recusa da audiência, por meio de enquetes instantâneas, votações ou amostragens da receptividade de determinado conteúdo. Ao passar pelo canal, o usuário poderá consultar um gráfico da receptividade do programa gerado pela manifestação de outros telespectadores, permitindo à emissora redefinir a sua condução e modificar o enfoque ou mesmo a profundidade da abordagem daquela exibição.

O Video-on-demand and Near-video-on-demand é uma possibilidade de acesso a conteúdos disponíveis em um repositório, que poderá ser a própria emissora ou provedores específicos, para que o usuário os recupere conforme seu interesse, necessidade e tempo. O recurso pode ser combinado com a elaboração personalizada do guia de conteúdo, mencionada anteriormente. Os repositórios serão uma forma de acesso a conteúdos que certamente poderão contribuir com o contexto educativo, como será visto depois.

Personal Video Recorders é o nome do sistema que permite o congelamento (pausa) e posterior disparo de um conteúdo televisivo, mesmo quando exibido pela primeira vez ou em transmissões ao vivo. O dispositivo simplesmente grava o programa em uma 
memória local, a partir do ponto em que é acionado. A capacidade de armazenamento depende do hardware utilizado. Outra funcionalidade permite que se grave uma programação enquanto se assiste a uma outra, e passe a exibi-la quando for conveniente.

Esses recursos poderão ou não ser adotados no sistema brasileiro de televisão digital interativa, ou ainda poderão ser incorporados conforme a capacidade de sua absorção pelos usuários e a viabilização econômica por parte das emissoras e provedores dos conteúdos e serviços. A sua utilização no contexto educacional, entretanto, está relacionada com a programação de cada emissora. Isso quer dizer que um canal poderá utilizá-los com fins puramente mercadológicos e de consumo enquanto outro, de natureza educativa, poderá utilizá-los tendo em vista um maior aproveitamento daquele conteúdo pelo usuário na construção e manipulação do conhecimento.

Espera-se, portanto, que a migração das emissoras pré-existentes ao novo modelo preveja a utilização destes recursos apresentados por Gawlinski e de outros que certamente estarão disponíveis. Podemos prospectar que as emissoras educativas irão propiciar ao telespectador formas de acesso a programas culturais interativos e de entretenimento educativo numa perspectiva de utilização da televisão como aparato para uma efetiva promoção social em um novo contexto inclusivo.

Na perspectiva dos repositórios de programas, temos as próprias emissoras e provedores como atores principais da promoção desses novos usos para os conteúdos televisivos, a partir dos recursos próprios da televisão digital apresentados anteriormente neste estudo. Um acervo fílmico com certeza pode contribuir com o acesso ao conhecimento, se forem facilitadas as formas de recuperação desses conteúdos. Ainda assim, vemos também na migração ao sistema digital de televisão das emissoras de caráter explicitamente educativo, como as televisões universitárias, por exemplo, uma forma real de multiplicação desses usos.

A ABTU - Associação Brasileira de Televisão Universitária articula, desde 2003, a criação da RITU - Rede de Intercâmbio de Televisão Universitária, para a difusão dos programas de televisão produzidos pelos associados e para que sirva de apoio à programação e distribuição dos canais educativos ou comunitários em operação no Brasil ${ }^{7}$. O presidente da ABTU em maio de 2005, Gabriel Priolli, aposta na "garantia de que haverá espaço [na tv

\footnotetext{
${ }^{7}$ Informações sobre a Ritu podem ser encontradas no sítio da ABTU na Internet, pelo endereço http://www.abtu.org.br/ritu/rituHome.asp
} 
digital] para os canais universitários que hoje estão limitados à tv a cabo" (PRIOLLI, 2005) e confirma o empenho da entidade para que os canais adicionais do sistema digital de televisão sejam ocupados por emissoras universitárias e não-comerciais, de interesse público, como os canais comunitários, legislativos institucionais e os educativo-culturais.

Uma rede de intercâmbio e difusão dos programas das televisões universitárias e outras emissoras apontadas pelo presidente da ABTU é perfeitamente plausível com o sistema de televisão digital, uma vez que resolve tecnicamente a questão do encapsulamento, envio e recepção dos conteúdos audiovisuais produzidos, funcionando como repositório acessível para a recuperação desses conteúdos.

Um outro exemplo da possibilidade de acesso aos repositórios de conteúdos tem sido testado desde dezembro de 2003, com a implementação da TV Escola Digital Interativa pelo Ministério da Educação, junto com a Secretaria de Educação a Distância. A iniciativa acontece muito antes da definição do padrão brasileiro e uma explícita desarticulação com o processo decisório do modelo de televisão digital do Governo certamente gera problemas e talvez explique as críticas que o sistema vem colecionando.

Trata-se do primeiro sistema de televisão digital interativa do país de uso exclusivo voltado à educação. O projeto é uma expansão da TV Escola, que atende cerca de 42 mil escolas equipadas com televisor, vídeo-cassete, antena parabólica e receptor.

O sistema original analógico permite a gravação dos programas de televisão, recebidos via satélite, em fita de vídeo, para posterior aproveitamento ou exibição. O novo sistema possibilita ao educador o acesso a uma variedade de informações e serviços que são gravados na memória do mesmo aparelho que recebe o sinal, em um disco rígido (HD). Os dados ficam armazenados por até 7 dias, mas podem ser gravados em CD e executados no próprio sistema, em computadores ou em reprodutores de DVD.

O sistema também oferece o recurso do canal de retorno, que permite alguma interatividade pela televisão digital: possibilita ao usuário interagir não somente com o sistema, mas também enviar dados para os provedores de conteúdo. Diferentemente do sistema original analógico, a TV Escola Digital Interativa possibilita a transmissão de conteúdos complementares, como guias didáticos e de orientação, tabelas e questionários que 
poderão ser enviados de volta ao provedor do conteúdo, ou para a central de serviços prevista para ser instalada na Secretaria de Educação a Distância. ${ }^{8}$

O programa do governo quer implementar o novo sistema digital em todas as 180 mil escolas do Ensino Básico no Brasil em quatro anos, um desafio se for considerado que o sistema analógico, implantado em março de 1996, atingiu menos que 50 mil estabelecimentos no país (BASTOS, 2003). Na fase inicial, a TV Escola Digital Interativa abrange 18 escolas e sete unidades que oferecem acesso informatizado à comunidade, espalhados pelo Brasil.

Partindo da possibilidade de uso da televisão digital nesse contexto específico de ensino, em sala de aula, o CPqD também elaborou uma proposta de sistema para o apoio aos professores baseado na tv digital interativa para ser usado no futuro modelo, o SAPSA Serviço de Apoio ao Professor em Sala de Aula (PINTO et a.l., 2004). O sistema prevê a interação entre os alunos e um repositório de conteúdo multimídia didático, com a mediação do professor, e pretende atender os diferentes tipos de escola conforme sua inclusão em diversos contextos sociais e geográficos do país.

O primeiro tipo de escola atendida será aquele estabelecimento pequeno e que está geograficamente isolado ou afastado, em áreas rurais e em municípios cobertos por sinais de televisão terrestre, mas que não têm acesso a uma rede de telecomunicações. Não terá canal de retorno e a requisição dos conteúdos será feita pelo serviço de Correios.

O segundo tipo de escola se caracteriza pelo acesso a um canal de retorno convencional, via telefonia fixa, utilizado para a requisição de conteúdos adicionais ao repositório. O terceiro tipo está localizado em regiões urbanas com acesso a canais eficientes de retorno (banda larga ou fibra ótica) e tem possibilidade de não apenas adquirir conteúdos (download), mas também de enviar uma eventual produção local para o repositório (up-load), disponibilizando-a aos demais grupos de ensino.

O protótipo desse sistema será experimentado em duas escolas públicas do município de Campinas (SP), no distrito de Barão Geraldo, próximas a uma estação de envio de sinais instalada no CPqD (que se localiza nos arredores do bairro escolhido). Embora planejado para 2004, até maio de 2005 esse sistema não está disponível para conhecimento e estudo por parte de pesquisadores externos.

\footnotetext{
${ }^{8}$ Informações sobre o projeto TV Escola Digital Interativa podem ser encontradas pela Internet, no endereço http://www.naveducacao.org/, assim como no sítio do MEC.
} 
O último ponto a ser apresentado, proposto na pesquisa deste artigo, diz respeito a uma aplicação específica de conteúdo digital interativo que poderá ser utilizado no meio televisivo em questão e tem relação com as formas de educação informais ou com a formação continuada do aprendente. O documentário digital interativo é uma prospecção sobre a apropriação das possibilidades técnico-operacionais da televisão digital interativa pelo gênero documentário, consagrado como produto fílmico, a partir de uma lógica estruturada pelas roteirizações em suportes multimídias (SACRINI, 2004).

A partir dos estudos de Gosciola (2003) sobre como pensar os roteiros nas hipermídias e da evolução do gênero documentário, vinculada com a modernização dos aparatos tecnológicos, proponho uma reorganização do seu conteúdo, de forma a prever e incorporar em sua estrutura as informações e possibilidades extra-filme, que certamente serão aproveitadas em meios digitais que potencializam as utilizações dos recursos multimídias.

A nova modalidade [de documentário] herdará do cinema a leitura linear embora possibilite, também, interrupções para o acesso a informações outras, multimídias, com características de uma linguagem hipertextual e interativa, agregando as possibilidades da não-linearidade e muti-linearidade. Além disso, os dados de retorno poderão ser direcionados ao provedor do conteúdo, conferindo ao documentário uma possibilidade didático-pedagógica como nunca antes experimentada pelo gênero (SACRINI, 2004).

Essa possibilidade de fruição do documentário numa televisão digital, por exemplo, vai depender do empenho e da transformação do olhar do produtor na incorporação, ao roteiro e ao conteúdo, de novos dados (extras, textos, fichas técnicas, interações educativas, etc) que tenham um caráter de aprofundamento do assunto apresentado no filme, e que contribuam na consolidação das novas formas de acesso, construção e transformação do conhecimento.

\section{CONCLUSÃO}

O andamento dos estudos sociais e tecnológicos expresso nos documentos do $\mathrm{CPqD}$, somado às articulações governamentais em torno da definição de um padrão para o Sistema Brasileiro de Televisão Digital, aponta um caminho sem volta em relação à transformação da televisão brasileira, principalmente enquanto possibilidade de inclusão social e uso educativo.

Esse empenho é certamente o principal enfoque das comunicações e decretos oficiais, que parecem ter a intenção de agregar ao instrumento uma capacidade de aumento da 
inclusão digital para conseqüente diminuição das diferenças sociais no país, o que merece um estudo específico. Entretanto, para a concretização desses objetivos, os educadores e as instituições de ensino devem não somente acompanhar, mas alocarem-se como atores efetivos do processo decisório e interlocutores contundentes dos debates desenvolvidos.

Partimos, nesta pesquisa, das informações existentes e expressas nos documentos sobre as reais possibilidades de aplicação dos novos recursos televisivos no contexto apenas informal dos processos educativos. Foram apresentadas algumas possibilidades potenciais de uso cultural e de acesso ao conhecimento da ferramenta, sem ainda abordar os usos didáticos específicos, estudo que deverá ainda ser desenvolvido.

Mesmo assim, já se vislumbra uma possibilidade de apropriação positiva dos recursos pelas emissoras e potenciais provedores de conteúdos. A ampliação do número de canais com a possibilidade da ocupação desse espaço pelas emissoras comunitárias, educativas ou redes de intercâmbio de conteúdos educativos é uma oportunidade que não pode ser desconsiderada pelos interessados na promoção social deste país.

Almeja-se, ainda, que se possa apostar um dia na utilização plena das possibilidades da televisão digital enquanto nó hipertextual de uma grande rede. Somente nesse sentido se dará espaço e voz para grupos e indivíduos que passariam a produzir seus próprios conteúdos que, disponíveis a outros grupos, promoveriam uma visão crítica sobre esta sociedade que tem no audiovisual sua principal fonte de consumo, entretenimento e, por que não, de acesso ao conhecimento.

\section{REFERÊNCIAS}

AMARAL, S. F.; PACATA, D. M. A TV Digital Interativa no espaço educacional. Jornal da Unicamp, Campinas, edição 229, de 15 a 21 set. 2003.

BASTOS, Alessandra. TV digital revolucionará a escola pública brasileira. Agência Brasil - Centro de Imprensa. Disponível em: <http://www.radiobras.gov. br/centro\%20imprensa/tv_digital_231203/mat_tvdigital2.php>, 23 dez. 2003.

BECKER, V.; MONTEZ, C. TV digital interativa: conceitos, desafios e perspectivas para o Brasil. Florianópolis: 12TV, 2004.

BRASIL. Ministério das Comunicações. Exposição de motivos. $n^{0}$ 1247, de 06 de setembro de 2002. 
. Ministério das Comunicações. Atos do poder executivo. Telecomunicações: TV Digital. Decreto nº 4901, 26 nov. 2003. Edição Número 231, 27 nov. 2003.

CASTELLS, M. A sociedade em rede. 8. ed. rev. ampl. São Paulo: Paz e Terra, 2005. v.1.

CPQD. Modelo de implantação da TV digital no Brasil: produto I - abordagem conceitual e analítica, 2002a.

Modelo de implantação da TV digital no Brasil: produto II - panorama mundial da implantação da tecnologia digital na transmissão terrestre de televisão, 2002b.

. Modelo de implantação da TV digital no Brasil: produto III - análise das condições brasileiras para a introdução da tecnologia digital na transmissão terrestre de televisão, 2002c.

Em busca do padrão nacional da TV Digital. Disponível em <http://www. cpqd.com.br/sbtvd-prod/noticias_view1.php?id=136>. Acesso em: 05 mar. 2005a.

Cadeia de valor. Versão PD.30.12.36a .0002A/RT-02-AA. Disponível em: $<$ http://sbtvd.cpqd.com.br>. Acesso: 05 mar. 2005b.

FNDC. Fórum Nacional pela Democratização da Comunicação. Clipping do dia. 26 abr. 2005a.

Fórum Nacional pela Democratização da Comunicação. Boletim de divulgação. $n^{\circ}$ 50, 05 mai. 2005b.

GAWLINSKI, M. Interactive television production. Oxford: Focal Press, 2003.

GOSCIOLA, V. Roteiro para as novas mídias: do game à tv interativa. São Paulo: Editora Senac, 2003.

LAKATOS, E. M.; MARCONI, M. A. Metodologia do trabalho científico. 6. ed. rev. ampl. São Paulo: Atlas, 2001.

LÉVY, P. As tecnologias da inteligência: o futuro do pensamento na era da informática. Rio de Janeiro: Editora 34, 2000.

PINTO, J. C. et al. Serviço de Apoio ao Professor em Sala de Aula : SAPSA.

CPqD/Funttel. Campinas, 2004.

PRIOLLI, G. Entrevista concedida dobre TV Digital e TVs Universitárias. Disponível em $<$ http://www.abtu.org.br/arquivos_tv_digital.asp> Acesso em: 09 mai. 2005.

SACRINI, M. Perspectivas do gênero Documentário pela apropriação de elementos de linguagem da TV Digital Interativa. ETD Educação Temática Digital, Campinas, SP, v.5, n.2, p. 7-22, 2004. 
